\title{
Aspergillus flavus in Soils and Corncobs in South Texas: Implications for Management of Aflatoxins in Corn-Cotton Rotations
}

\author{
Ramon Jaime-Garcia and Peter J. Cotty, United States Department of Agriculture-Agricultural Research Service \\ and Division of Plant Pathology and Microbiology, University of Arizona, Tucson 85721
}

\begin{abstract}
Jaime-Garcia, R., and Cotty, P. J. 2004. Aspergillus flavus in soils and corncobs in South Texas: Implications for management of aflatoxins in corn-cotton rotations. Plant Dis. 88:1366-1371.

Aspergillus flavus causes aflatoxin contamination in both cottonseed and corn. Corn-cotton rotations are common in South Texas, where reduced tillage frequently results in long-term residence of corncobs on soil surfaces. Corncobs are colonized by A. flavus either prior to harvest or while in the soil. This study sought to determine the potential of corncobs as sources of inoculum for cotton and corn in South Texas. A. flavus communities in corncob and soil samples were collected during the planting seasons of 2001 to 2003 from 29 fields extending from Calhoun and Victoria Counties in the north to the Rio Grande Valley. In order to assess persistence of A. flavus in corncobs, A. flavus communities in corncobs and soil were contrasted every 2 to 3 months in four fields throughout the 3-year study. To assess seasonal variation, similar contrasts were performed in two fields on a biweekly basis. The results indicate that corncobs are major sources of A. flavus inoculum. Corncobs from the previous season contained, on average, over 190 times more A. flavus propagules than soil from the same field, and 2-year-old corncobs still retained 45 times more propagules than soil. There was no significant difference in the incidence of A. flavus strain $\mathrm{S}$ on corncobs and soil. The quantity of A. flavus in corncobs decreased with corncob age $\left(r^{2}=0.54 ; P=0.002\right)$.
\end{abstract}

Additional keywords: pith, placenta, sclerenchyma

Aspergillus flavus is the main causal agent of aflatoxin contamination in several agricultural products, including cottonseed and corn $(2,11,15,22)$. Aflatoxins are toxic fungal metabolites that are limited in food and feed by government regulations throughout most of the world $(26,32)$.

A. flavus can be divided into $\mathrm{S}$ and $\mathrm{L}$ strains based on morphologic, genetic, and physiologic criteria $(3,10,16,17)$. The $S$ strain produces numerous small sclerotia (average diameter $<400 \mu \mathrm{m}$ ) and high levels of aflatoxins, whereas the L strain produces fewer, larger sclerotia (average diameter $>400 \mu \mathrm{m}$ ) and, on average, less aflatoxin $(10,13,18)$. Aflatoxin producers from North America with the S strain morphotype produce only B aflatoxins (8). A.

Corresponding author: P. J. Cotty

E-mail: pjcotty@ srrc.ars.usda.gov

This work was supported in part by grants from the Cotton Foundation, the Texas State Support Program of Cotton Incorporated, the Texas Cottonseed Crushers Association, and the United States Department of Agriculture Multi-Crop Aflatoxin Working Group.

Accepted for publication 20 July 2004

Publication no. D-2004-1018-01R

This article is in the public domain and not copyrightable. It may be freely reprinted with customary crediting of the source. The American Phytopathological Society, 2004. flavus S strain isolates have been implicated as important aflatoxin producers in several areas worldwide, including Arizona $(10,13,25)$, Texas $(14,19,20)$, Louisiana, Mississippi, and Alabama (13) in the United States, Thailand in Southeast Asia (28), and Argentina in South America (24).

A. flavus typically lives as a saprophyte in the soil depending on organic matter to propagate and survive $(1,6)$. Crop residues, including corncobs, are the main source of organic matter in soils where corn crops are produced and these support large populations of microorganisms $(9,23,29,30)$. Unlike most crop residues that readily decay in agricultural soils (23), corncobs reside in soil for several years before being totally decomposed $(5,7)$. Harvest and cultivation practices influence how long crop residues reside in soil (7). Cultivation practices vary widely in South Texas, with reduced tillage practices being very common in some areas. A high percentage of corncobs are colonized by A. flavus before their incorporation into soil (33), making them a potentially important source of inoculum for susceptible crops planted in fields previously cropped to corn. These infested corncobs may play a major role as reservoirs of A. flavus in corn-cotton rotations. The objective of this study was to examine the potential importance of corncobs both as a source of inoculum of $A$. flavus in corn-cotton crop rotations and as a refuge for the long-term maintenance of
A. flavus communities in agricultural environments in South Texas.

\section{MATERIALS AND METHODS}

In order to assess the potential importance of corncob residue in harboring $A$. flavus during corn-cotton rotations in South Texas, A. flavus resident in corncobs and soils was quantified during the 2001 to 2003 seasons.

Sample processing and isolation of fungi. Both the corncob and soil samples were oven dried at $48^{\circ} \mathrm{C}$ for $48 \mathrm{~h}$ before processing. Soil samples were placed inside a plastic bag, hammered to break clumps, and passed through a no. 12 sieve (1.7-mm opening). Corncob samples were ground to a fine powder in a laboratory mill (IKA Labortechnik MF10 basic S1; IKA-Werke GmbH \& Co. KG, Staufen, Germany). Both the sieve and the mill were vacuumed to remove loose contaminants and washed with ethanol to kill contaminating fungal spores after processing each sample. A. flavus was isolated from both substrates by dilution plating onto a modified rose-Bengal agar (12). Dilution plates were incubated for 3 days at $37^{\circ} \mathrm{C}$. For each sample, 12 to 16 discrete Aspergillus section Flavi colonies were subcultured on $5 / 2$ agar (5\% V8 juice and $2 \%$ agar, $\mathrm{pH}$ 5.2) for 5 to 7 days at $31^{\circ} \mathrm{C}$ and assigned either to A. flavus $\mathrm{S}$ or $\mathrm{L}$ strains, A. tamarii, or A. parasiticus on the basis of colony characteristics and strain morphology (10). The quantities of A. flavus in soil and corncob samples were calculated as the number of CFU of $A$. flavus per gram. The percent of isolates belonging to the highly aflatoxigenic $\mathrm{S}$ strain of A. flavus (percent $S$ ) was obtained by dividing the number of strain $\mathrm{S}$ isolates by the total number of $A$. flavus isolates and multiplying by 100 .

Population structure of $A$. flavus on corncobs and soil. To determine the structure of A. flavus communities in soils and corncobs in South Texas, samples of soil and corncobs were collected from 29 fields before they were planted in spring 2001, 2002, and 2003. The corncobs collected were from corn crops grown either the previous season or two seasons prior. In order to compare the structures of A. flavus communities residing on corncobs with those in soils over time, two separate studies were performed. First, to determine the fluctuations in A. flavus populations between seasons, four fields were sampled 
every 2 to 3 months over three crop seasons. In the second study, the fluctuations of A. flavus populations over a single season were determined by sampling corncobs and soil biweekly during the season of 2002. For the second study, two fields, one with 1-year-old corncobs from the 2001 season and one with 2-year-old corncobs from the 2000 season, were sampled in 2002.

Corncob inoculation. To assess the growth and reproduction of A. flavus on corncobs after delivery to the soil, corncob inoculation experiments were performed. Whole corncobs from recently harvested fields were collected from the soil surface in July 2002. The corncobs were washed with a $0.05 \%$ Tween 80 solution five times. Treatments tested were (i) washed corncobs, (ii) washed corncobs autoclaved for 60 min at $121^{\circ} \mathrm{C}$, (iii) washed corncobs autoclaved as above and inoculated with $A$. flavus AF36, and (iv) corncobs as they were collected from the field (control). The inoculation of the corncobs was performed by dipping $1 \mathrm{~cm}$ of both ends of the corncobs into a 48-nephelometric turbidity units (NTU) spore suspension of $A$. flavus strain AF36. The NTU were measured with an Orbeco-Helling digital direct-reading turbidimeter (Orbeco Analytical Systems Inc., Farmingdale, NY). The corncobs from the other treatments were dipped in sterile water. Three replicates of each treatment were incubated individually in wet chambers (a steam-sterilized, widemouth bottle containing a small bottle full of sterile water was used to provide humidity) at $37^{\circ} \mathrm{C}$ for 7 days (experiment 1 ) or 5 days (experiment 2). After incubation, the corncobs were washed with $0.05 \%$ Tween 80 and the washings were subjected to dilution plating on the modified rose-Bengal isolation medium (12).

Distribution of $A$. flavus within corncobs. A. flavus was isolated from separated pith, sclerenchyma, and placenta of corncobs obtained from a South-Texas field in 2002. Corncobs were dissected to separate these tissues, which were ground to a fine powder, suspended in a $0.01 \%$ Triton $\mathrm{X}$ solution, and subjected to dilution plating as above. Tests were performed twice.

Statistical analyses. Analysis of variance (ANOVA) was performed on all data with the general linear model (GLM) procedure of SAS (version 8.0; SAS Institute, Cary, NC). The GLM procedure of SAS uses the method of least squares to fit data to a general linear model. It is suitable for unbalanced data. CFU/g data were transformed to the natural logarithm for the analyses. Tukey's honestly significant difference (HSD) tests were performed to compare treatment means at the 5\% level. Linear regression analyses and exponential analyses were performed with either SAS (version 8.0) or Grapher (version 4.0; Golden Software Inc., Golden, CO). On the SAS system, the GLM procedure was used for linear regression analysis and the nonlinear regression (NLIN) procedure for the exponential decay analysis.

\section{RESULTS}

Structure of A. flavus communities in corncobs and in soil. In South Texas, corncobs harbored, on average, 192-fold more propagules of A. flavus than soil (273,403 versus 1,425 CFU/g; Table 1; Fig. 1A). However, when comparisons of $\mathrm{CFU} / \mathrm{g}$ were made on a field-by-field basis, corncobs harbored up to 6,890 -fold more A. flavus propagules than the corresponding soil in a single field (Fig. 1). Furthermore, corncobs that had been in the soil for 2 years still had, on average, 44 times more A. flavus propagules than soil (Table 1). Two-year-old corncobs in individual fields had up to 70-fold more A. flavus than the corresponding soil (Fig. 1A). Over $60 \%$ of corncob samples (50\% of fields) contained more than $25,000 \mathrm{CFU} / \mathrm{g}$, while about $60 \%$ of soil samples ( $50 \%$ of fields) contained fewer than 1,000 CFU/g (Fig. 1A). There were no significant differences in strain composition between populations of A. flavus in corncobs and soil as indicated by percentages of the high aflatoxinproducing S strain (Fig. 1B). The average incidences of the $\mathrm{S}$ strain in South Texas for corncobs and soil were 14.7 and $18.1 \%$, respectively (Table 1). Even though fields containing second-year corncobs had a higher percent $\mathrm{S}$ for both corncob and soil samples, these differences were not statistically significant (Table 1).

A. flavus on corncobs over time. In the current study in South Texas, NLIN analysis indicated that the quantity of A. flavus on corncobs decreased exponentially as a function of corncob age when the studies were sufficiently long (Fig. 2). However, over short periods (around 3 months), the quantity of $A$. flavus did not always decrease (Fig. 3). A. flavus populations on corncobs left in the field declined exponentially after harvest. NLIN analysis indicated that CFU of $A$. flavus from corncobs left in the field decreased as a function of corncob age. In the first 4 months after harvest, the quantity of $A$. flavus was highest, ranging from 100,000 to a few million CFU/g, depending on corncob source field, followed by an exponential decrease from the fourth month until around the ninth month. After 9 months, the quantity of $A$. flavus on corncobs decreased at lower rates (Fig. 2).

Corn cropping year had a major effect on the quantity of A. flavus on corncobs left in the field but not on the strain composition or the quantity of A. flavus in the soil (Table 2). The 1-year-old corncobs sampled in 2003 (corncobs from fields cropped with corn in 2002) had significantly higher quantities of $A$. flavus (average $=1,177,000 \mathrm{CFU} / \mathrm{g}$ ) than either 1 year-old corncobs sampled in 2001 or 2002 or 2-year-old corncobs sampled from 2001 to 2003 (Table 2; Fig. 1A).

When corncobs from the previous season (1-year-old corncobs) and from two seasons previous (2-year-old corncobs) were monitored every 2 weeks during the cotton and corn crop seasons, A. flavus CFU decreased as a function of time. However, the pattern of decrease was variable and did not follow a definite model (Fig. 3); the decrease in CFU/g during the first year after harvest fit an exponential model best, while the decreases during the second year best fit a linear model (Fig. 3). The quantity of $A$. flavus in soils was less variable and the trends were not as strong as for corncobs, and regression analysis failed to provide a strong model (Fig. 3).

A. flavus from inoculated corncobs. Corncobs inoculated with A. flavus produced significantly higher CFU/g than uninoculated nonsterile controls. No $A$. flavus was isolated from the washed and sterilized control corncobs from either experiment (Table 3). Field-collected corncobs inoculated with A. flavus supported up to $25.4 \times 10^{6} \mathrm{CFU} / \mathrm{g}$ over a 5 -day incubation period and up to $6.5 \times 10^{9} \mathrm{CFU} / \mathrm{g}$ during a 7-day incubation period. Inoculated corncobs produced at least $11.4 \times 10^{6}$ $\mathrm{CFU} / \mathrm{g}$ and uninoculated corncobs from South Texas were sufficiently associated with A. flavus to produce up to $9.17 \times 10^{5}$ $\mathrm{CFU} / \mathrm{g}$ in a 7-day incubation period.

A. flavus from different parts of the corncob. Two separate experiments indicated that the corncob placenta harbors higher quantities of $A$. flavus, with an average of $16,675 \mathrm{CFU} / \mathrm{g}$ compared with the pith and sclerenchyma parts, which average 2,208 and $701 \mathrm{CFU} / \mathrm{g}$, respectively (Table 4). The incidence of the $\mathrm{S}$ strain did

Table 1. Percentage of Aspergillus flavus isolates belonging to the S strain (percent S), and total CFU of A. flavus from corncobs and soils from South Texas ${ }^{\mathrm{y}}$

\begin{tabular}{|c|c|c|c|c|}
\hline \multirow[b]{2}{*}{ Years postharvest ${ }^{\mathrm{z}}$} & \multicolumn{2}{|c|}{ Percent S (\%) } & \multicolumn{2}{|c|}{ A. flavus (CFU/g) } \\
\hline & Corncob & Soil & Corncob & Soil \\
\hline One $(n=146)$ & $12.3 \mathrm{~B}(\mathrm{a})$ & 15.6 B (a) & 319,403 A (a) & 1,424 B (b) \\
\hline Two $(n=34)$ & $25.8 \mathrm{~A} \mathrm{(a)}$ & 28.6 A (a) & $63,527 \mathrm{~B}(\mathrm{a})$ & $1,430 \mathrm{~A}(\mathrm{~b})$ \\
\hline Average $(n=180)$ & $14.7(\mathrm{a})$ & $18.1(\mathrm{a})$ & 273,403 (a) & $1,425(b)$ \\
\hline
\end{tabular}

y Averages with the same letter are not significantly different by Tukey's honestly significant difference test $(\alpha=0.05)$. Uppercase letters indicate differences between periods of corncob residence (rows). Lowercase letters in parenthesis indicate differences between corncob and soil (columns).

z Years after corn harvest: number of years between when the corn was harvested and when the corncobs were collected; $n=$ the number of pairs of corncob and soil samples. 

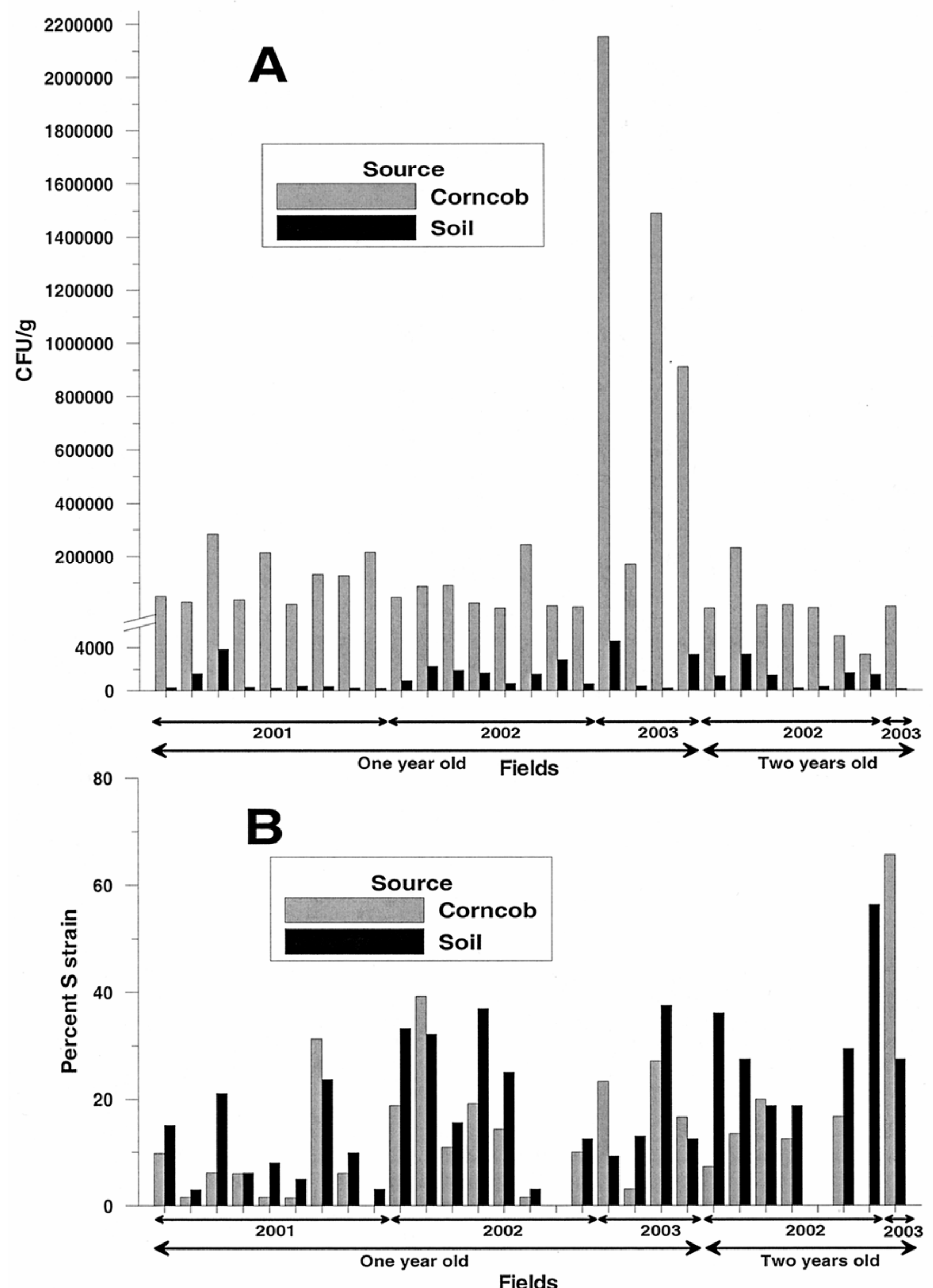

Fig. 1. A, CFU of Aspergillus flavus per gram of corncob (gray bars) or soil (black bars) and B, percentage of isolates of A. flavus $\mathrm{S}$ strain in corncob or soil from fields in South Texas. 
not differ significantly among either corncob sections or tissues (Table 4).

\section{DISCUSSION}

Results presented here on A. flavus communities associated with corncobs and soils in South Texas indicate that corncobs might be a major component of aflatoxin contamination cycles in corn-cotton rotations in South Texas. The large quantities of A. flavus observed in corncobs, even after the corncobs have been in the soil for 2 years (Fig. 1; Tables 1 and 2), indicate that corncobs support survival and propagation of this fungus in the soil over relatively long periods. Additionally, it is likely that much of the A. flavus resident in the soil is a result of corncobs and corncob fragments and other corn debris. Organic matter supports survival and reproduction of microorganisms in the soil $(9,23,29,30)$, including A. flavus $(1,6)$. Some farming operations in South Texas have "low-till" or "no-till" practices that may leave corncobs relatively undisturbed on soil surfaces (7). Corncobs left on soil surfaces may decompose slowly and remain for long periods $(5,7)$ while supporting large populations of fungi, including $A$. flavus $(27,33)$, as indicated by the large quantities of CFU obtained when corncobs were inoculated (Table 3). Corncobs contribute significantly to the biomass in corn fields (about 1,500 kg/ha). Based on the average number of propagules recovered from corncobs during this study, corn fields would have, on average, $4.8 \times 10^{11} \mathrm{~A}$. flavus propagules per hectare for the next season produced on corncobs. Adopting harvest and cultivation practices that break up and incorporate corncobs below the soil surface should result in reduced residence of corncobs (7) and, thus, reduce the exposure of subsequent corn or cotton crops to aflatoxin-producing fungi.

Differences in $\mathrm{S}$ strain incidence in corncobs between the first and second years (Table 1) might be due to location of the fields rather than the length of corncob residence. Most fields with 2-year-old

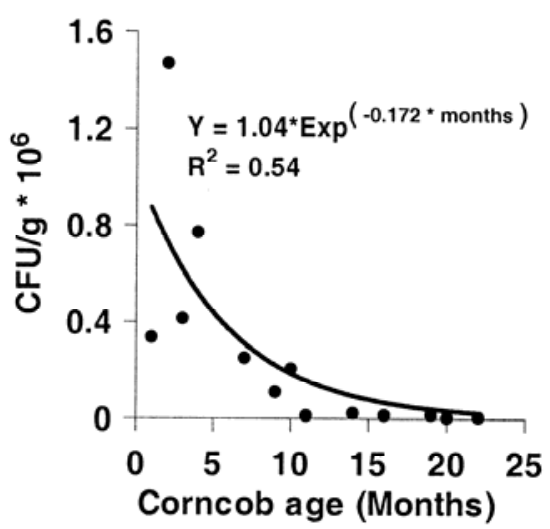

Fig. 2. CFU of Aspergillus flavus per gram of corncob collected from commercial fields in South Texas as a function of corncob age. corncobs were located between Corpus Christi and Port Lavaca (in the counties of Nueces, San Patricio, Refugio, Victoria, and Calhoun), an area known to have higher S strain percentages than elsewhere in South Texas (21), whereas the fields containing 1-year-old corncobs were located throughout South Texas, which includes areas with relatively low $\mathrm{S}$ strain percentages (21). However, $\mathrm{S}$ strain isolates produce very high levels of aflatoxins and numerous small sclerotia, both factors that might facilitate long-term survival.

Year of corn crop production had a major effect on the quantity of $A$. flavus on corncobs left in the field but not on $\mathrm{S}$ strain incidence or the quantity of $A$. flavus in the soil (Table 2). This might be explained by year-to-year variation in rates of infection of corncobs before harvest, especially when the harvest is delayed by weather and the mature ears are wetted (31) by rain (data not shown). The 1-year-old corncobs sampled in 2003 were from fields cropped with corn in 2002, and they had significantly higher quantities of $A$. flavus than any other season examined (Table 2). Corn harvest in the 2002 season was delayed about 1 month because of rain, and many corn fields were lost due to high levels of aflatoxin. Corn crops with aflatoxin levels exceeding $500 \mathrm{ng} / \mathrm{g}$ were incorporated into the soil without harvest. However, large quantities of corncobs were left on the surface of the soil-corncobs from such crops would be expected to have very large quantities of A. flavus. Growers forced by aflatoxin content to disc under crops prior to harvest should be encouraged to incorporate the crop below the soil surface as soon as possible. Unfortunately, in the very heavy soils predominant in parts of South Texas, deep plowing and debris incorporation may be prohibitively expensive.

The differences found among the quantities of A. flavus in the different corncob tissues (pith, sclerenchyma, and placenta; Table 4) might explain the rapid decline of A. flavus populations on corncobs as a function of corncob age (Fig. 2). The placenta had the highest quantities of propagules whereas the sclerenchyma had the lowest levels (Table 4). Interestingly, the 2-year-old corncobs collected from the field were composed mainly of sclerenchyma (data not shown), the hardest part of the corncob (33). This means that both the placenta and the pith sections (soft tissue) of the corncob were decomposed
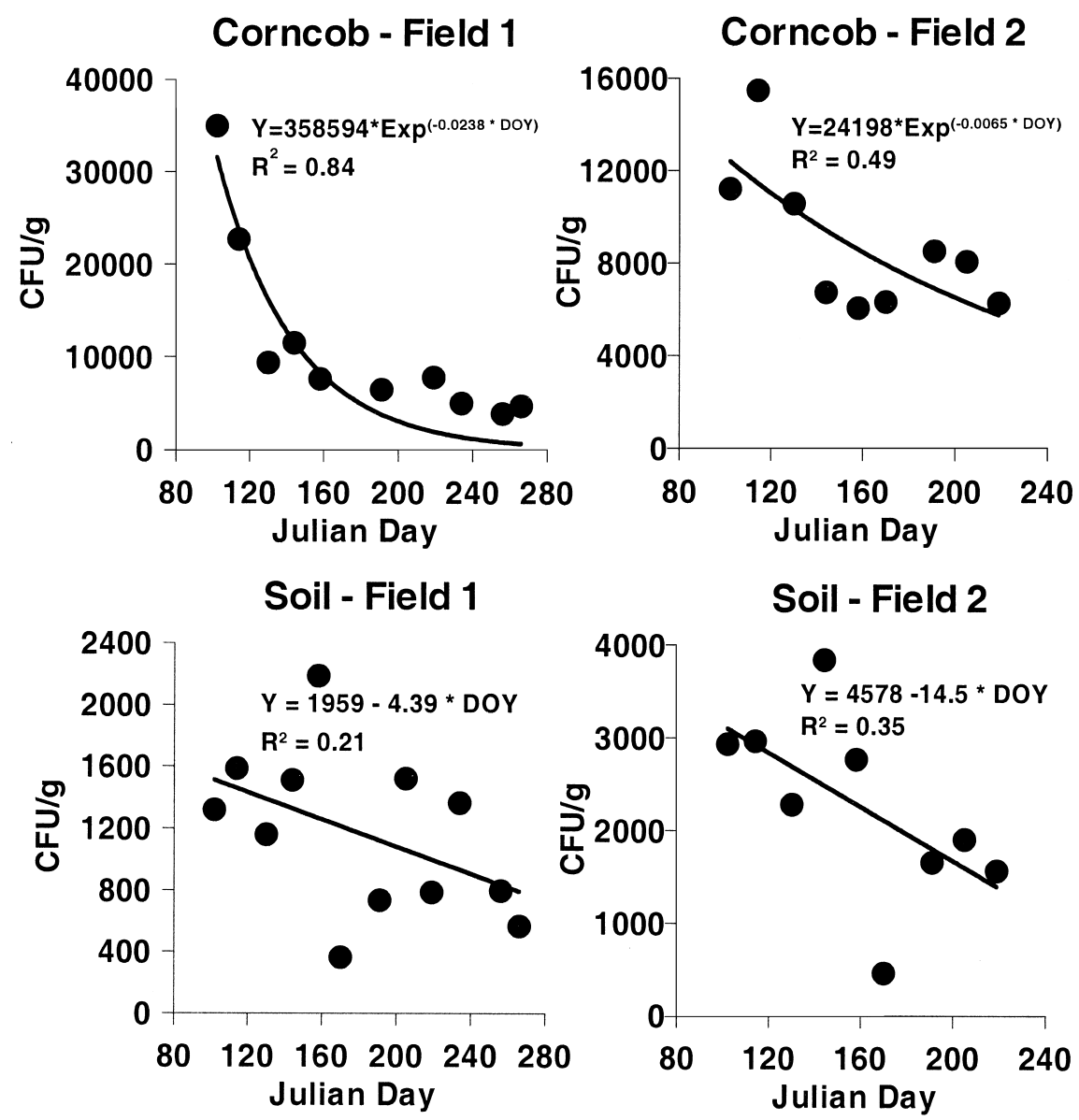

Fig. 3. CFU of Aspergillus flavus per gram of corncob or soil from two fields in South Texas sampled on a biweekly basis. Field 1 was cropped to cotton during the season of study and had corncobs from the previous season (1 year old) and field 2 was cropped to corn during the season of study, with cotton the previous season and had corncobs from the season 2 years prior (2 years old). 
much faster within the first year. Thus, declines in the quantities of A. flavus in corncobs are partially attributable to decomposition of the placenta.

The $\mathrm{S}$ strain is the major contributor to the average aflatoxin-producing potential of fungal communities resident in South Texas (13) and, therefore, is the primary target of biocontrol efforts directed at reducing aflatoxin-producing potential with atoxigenic strains of $A$. flavus. Reductions in average aflatoxin-producing potential result in reduced contamination of crops (4). Failure of corncobs to provide either selective advantage or disadvantage for the $S$ strain suggests that corncobs will not interfere with this biocontrol strategy over the long run. However, corncobs provide an avenue for long-term retention of highly toxigenic community structures, and strategies must be designed to colonize corncobs with biocontrol strains of $A$. fla$v u s$ as early as possible. If corncobs are successfully colonized by biocontrol strains of A. flavus, the data presented here suggest that corncobs will facilitate longterm retention of these beneficial strains across crop rotations.

\section{ACKNOWLEDGMENTS}

We thank Jeff Nunley and the South Texas Cotton and Grain Association for assistance in several aspects of the work, and S. Williams for technical assistance.

\section{LITERATURE CITED}

1. Agrios, G. N. 1997. Plant Pathology, Fourth Edition. Academic Press, San Diego.

2. Anderson, H. W., Nehring, E. W., and Wicher, W. R. 1975. Aflatoxin contamination of corn in the field. J. Agric. Food Chem. 23:775-782.

3. Bayman, P., and Cotty, P. J. 1993. Genetic diversity in Aspergillus flavus: association with aflatoxin production and morphology. Can. J. Bot. 71:23-31.

4. Bhatnagar, D., Cotty, P. J., and Cleveland, T. E. 2001. Genetic and biological control of aflatoxigenic fungi. Pages 207-240 in: Microbial Food Contamination. C. L. Wilson and S. Droby, eds. CRC Press, Boca Raton, FL.

5. Broder, M. W., and Wagner, G. H. 1988. Microbial colonization of corn, wheat and soybean residue. Soil Sci. Soc. Am. J. 52:112-117.

6. Bruehl, G. W. 1987. Soilborne Plant Patho-

Table 2. Percentage of Aspergillus flavus belonging to the $\mathrm{S}$ strain and CFU of A. flavus per gram of corncob or soil collected from 29 fields with corncobs from the previous season or from 2 years prior in South Texas during the seasons of 2001 to 2003

\begin{tabular}{|c|c|c|c|c|}
\hline \multirow[b]{2}{*}{ Year } & \multicolumn{2}{|c|}{ Corncob $^{\mathrm{z}}$} & \multicolumn{2}{|c|}{ Soil $^{\mathrm{z}}$} \\
\hline & 1-year-old & 2-year-old & 1-year-old & 2-year-old \\
\hline \multicolumn{5}{|c|}{ Percent S } \\
\hline 2001 & $7 \mathrm{~A}$ & ND & $10 \mathrm{~B}$ & ND \\
\hline 2002 & 17 A (a) & $11 \mathrm{~B}$ (a) & 23 A (a) & 29 A (a) \\
\hline 2003 & 17 A (b) & 66 A (a) & $17 \mathrm{AB}(\mathrm{a})$ & $27 \mathrm{~A} \mathrm{(a)}$ \\
\hline \multicolumn{5}{|c|}{$\mathrm{CFU} / \mathrm{g} \times 1,000$} \\
\hline 2001 & $135 \mathrm{~B}$ & ND & $1 \mathrm{~B}$ & ND \\
\hline 2002 & 86 B (a) & $81.5 \mathrm{~A} \mathrm{(a)}$ & 1.6 A (a) & $1.8 \mathrm{~A}(\mathrm{a})$ \\
\hline 2003 & 1,177 A (a) & $9.4 \mathrm{~A}(\mathrm{~b})$ & $2.1 \mathrm{~A}(\mathrm{a})$ & $0.1 \mathrm{~A}(\mathrm{~b})$ \\
\hline
\end{tabular}

${ }^{\mathrm{z}}$ For corncobs, age $=$ the period between when the corn was harvested and the corncobs were collected; soil samples were at the same location and time that corresponding corncobs were collected. Averages with the same letter are not significantly different by Tukey's honestly significant difference test $(\alpha=0.05)$. Capital letters indicate differences among years (Rows). Lower case letters in parenthesis indicate differences between periods of corncob residence (Columns). ND $=$ not determined.

Table 3. CFU of Aspergillus flavus per gram of corncob incubated at $37^{\circ} \mathrm{C}$ and $100 \%$ relative humidity ${ }^{\mathrm{z}}$

\begin{tabular}{lcc}
\hline Treatment & Experiment 1 & Experiment 2 \\
\hline Inoculated & $2,833,333,333 \mathrm{a}$ & $61,837,942 \mathrm{a}$ \\
Washed & $323,611 \mathrm{ab}$ & $63 \mathrm{bc}$ \\
Control & $37,777 \mathrm{bc}$ & $1,590 \mathrm{~b}$ \\
Wash and autoclaved & $0 \mathrm{c}$ & $0 \mathrm{c}$ \\
\hline
\end{tabular}

${ }^{\mathrm{z}}$ Experiment 1 was incubated for 7 days and experiment 2 for 5 days. Data with the same letter are not significantly different by Tukey's honestly significant difference test $(\alpha=0.05)$.

Table 4. Percentage of the S strain of Aspergillus flavus and CFU of A. flavus per gram of corncob from the different corncob tissues ${ }^{\mathrm{z}}$

\begin{tabular}{lccccc}
\hline & \multicolumn{2}{c}{ Experiment 1 } & & \multicolumn{2}{c}{ Experiment 2 } \\
\cline { 2 - 3 } \cline { 5 - 6 } Corncob part & S strain (\%) & A.flavus $($ CFU/g) & & S strain $(\%)$ & A. flavus $($ CFU/g) \\
\hline Pith & $5.9 \mathrm{a}$ & $3,023 \mathrm{~b}$ & & $25.0 \mathrm{a}$ & $1,394 \mathrm{~b}$ \\
Sclerenchyma & $15.6 \mathrm{a}$ & $763 \mathrm{~b}$ & & $14.2 \mathrm{a}$ & $639 \mathrm{~b}$ \\
Placenta & $15.0 \mathrm{a}$ & $15,718 \mathrm{a}$ & & $9.4 \mathrm{a}$ & $17,631 \mathrm{a}$ \\
\hline
\end{tabular}

${ }^{\mathrm{z}}$ Data with the same letter are not significantly different by Tukey's honestly significant difference test $(\alpha=0.05)$.

gens. Macmillan Publishing Company, New York

7. Burgess, M. S, Mehuys, G. R., and Madramootoo, C. A. 2002. Decomposition of grain-corn residues (Zea mays L.): A litterbag study under three tillage systems. Can. J. Soil Sci. 82:127-138.

8. Cardwell, K. F., and Cotty, P. J. 2002. Distribution of Aspergillus flavus section Flavi among soils from the four agroecological zones of the Republic of Bénin, West Africa. Plant Dis. 86:434-439.

9. Cookson, W. R., Beare, M. H., and Wilson, P. E. 1998. Effect of prior crop residue management on microbial properties and crop residue decomposition. Appl. Soil Ecol. 7:179-188.

10. Cotty, P. J. 1989. Virulence and cultural characteristics of two Aspergillus flavus strains pathogenic on cotton. Phytopathology 79:808814.

11. Cotty, P. J. 1990. Effect of atoxigenic strains of Aspergillus flavus on aflatoxin contamination of developing cottonseed. Plant Dis. 74:233235.

12. Cotty, P. J. 1994. Comparison of four media for the isolation of Aspergillus flavus group fungi. Mycopathologia 125:157-162

13. Cotty, P. J. 1997. Aflatoxin-producing potential of communities of Aspergillus section Flavi from cotton producing areas in the United States. Mycol. Res. 101:698-704.

14. Cotty, P. J., Jaime-Garcia, R., and Kobbeman, K. 2001. The S strain of A. flavus in South Texas. (Abstr.) Phytopathology 91:S19.

15. Diener, U. S. 1989. Preharvest aflatoxin contamination of peanuts, corn and cottonseed: A review. Biodeterior. Res. 2:217-244.

16. Egel, D. S., Cotty, P. J., and Elias, K. S. 1994. Relationships among isolates of Aspergillus sect. Flavi that vary in aflatoxin production. Phytopathology 84:906-912.

17. Ehrlich, K. C., Montalbano, B. G., and Cotty, P. J. 2003. Sequence comparison of aflR from different Aspergillus species provide evidence for variability in regulation of aflatoxin production. Fungal Genet. Biol. 38:63-74.

18. Garber, R. K., and Cotty, P. J. 1997. Formation of sclerotia and aflatoxins in developing cotton bolls infected by the $\mathrm{S}$ strain of Aspergillus fla$v u s$ and potential for biocontrol with an atoxigenic strain. Phytopathology 87:940-945.

19. Horn, B. W., and Dorner, J. W. 1999. Regional differences in production of aflatoxin $B_{1}$ and cyclopiazonic acid by soil isolates of Aspergillus flavus along a transect within the United States. Appl. Environ. Microbiol. 65:14441449.

20. Jaime-Garcia, R., and P. J. Cotty. 2003. Aflatoxin contamination in commercial cottonseed in South Texas. Phytopathology 93:1190-1200.

21. Jaime-Garcia, R., and Cotty, P. J. 2004. Aspergillus flavus communities associated with commercial cottonseed in South Texas. (Abstr.) Phytopathology 93:S39.

22. Lillehoj, E. B. 1987. The aflatoxin-in-maize problem: The historical perspective. Pages 13-32 in: Aflatoxin in Maize: A Proceedings of the Workshop. M. S. Zuber, E. B. Lillehoj, and B. L. Renfro, eds. CIMMYT, Mexico, DF.

23. Neely, C. L., Beare, M. H., Hargrove, W. L., and Coleman, D. C. 1991. Relationships between fungal and bacterial substrate-induced respiration, biomass and plant residue decomposition. Soil Biol. Biochem. 23:947954.

24. Novas, M. V., and Cabral, D. 2002. Association of mycotoxin and sclerotia production with compatibility groups in Aspergillus flavus from peanut in Argentina. Plant Dis. 86:215219.

25. Orum, T. V., Bigelow, D. M., Cotty, P. J., and Nelson, M. R. 1999. Using predictions based on geostatistics to monitor trends in Aspergil- 
lus flavus strain composition. Phytopathology 89:761-769.

26. Park, D. L., Lee, L. S., Price, R. L., and Pohland A. E. 1988. Review of the decontamination of aflatoxin by ammoniation: current status and regulation. J. Assoc. Off. Anal. Chem. 71:685-703.

27. Royals, M. A., Getzy, D. M., and VandeWoude, S. 1999. High fungal spore load in corncob bedding associated with fungal-induced rhinitis in two rats. Contemp. Top. Lab. Anim. Sci. 38:64-66.

28. Saito, M., Tsuruta, O., Siriacha, P., Kawasugi, S., Manabe, M., and Buangsuwon, D. 1986.
Distribution and aflatoxin productivity of the atypical strains of Aspergillus flavus isolated from soils in Thailand. Proc. Jpn. Assoc. Mycotoxicol. 24:41-46.

29. Schomberg, H. H., and Steiner, J. L. 1997. Estimating crop residue decomposition coefficients using substrate-induced respiration. Soil Biol. Biochem. 29:1089-1097.

30. Sharma, S. K., Aggarwal, R. K., and Lodha, S. 1995. Population changes of Macrophomina phaseolina and Fusarium oxysporum f. sp. cumini in oil-cake and crop residue-amended sandy soil. Appl. Soil Ecol. 2:281-284.

31. Trenk, H. L., and Hartman, P. A. 1970. Effects of moisture content and temperature on aflatoxin production in corn. Appl. Microbiol. 19:781-784.

32. van Egmond, H. P. 2002. Worldwide Regulations for Mycotoxins. Pages 257-269 in: My cotoxins and Food Safety. J. W. DeVries, M

W. Trucksess, and L. S. Jackson, eds. Advances in Experimental Medicine and Biology. V. 504. Kluwer Academic/Plenum Publishers, New York.

33. Zummo, N., and Scott, G. E. 1990. Cob and kernel infection by Aspergillus flavus and Fusarium moniliforme in inoculated, fieldgrown maize ears. Plant Dis. 74:627-631. 